ARTICLE

https://doi.org/10.1038/s41467-019-09510-5

\title{
Scalable synthesis of ant-nest-like bulk porous silicon for high-performance lithium-ion battery anodes
}

Weili An (1) 1,2, Biao Gao ${ }^{1,3}$, Shixiong Mei ${ }^{1}$, Ben Xiang ${ }^{1}$, Jijiang Fu${ }^{1}$, Lei Wang ${ }^{2}$, Qiaobao Zhang ${ }^{4}$, Paul K. Chu (D) ${ }^{3}$ \& Kaifu Huo (1) ${ }^{2}$

Although silicon is a promising anode material for lithium-ion batteries, scalable synthesis of silicon anodes with good cyclability and low electrode swelling remains a significant challenge. Herein, we report a scalable top-down technique to produce ant-nest-like porous silicon from magnesium-silicon alloy. The ant-nest-like porous silicon comprising threedimensional interconnected silicon nanoligaments and bicontinuous nanopores can prevent pulverization and accommodate volume expansion during cycling resulting in negligible particle-level outward expansion. The carbon-coated porous silicon anode delivers a high capacity of $1,271 \mathrm{mAh} \mathrm{g}^{-1}$ at $2,100 \mathrm{~mA} \mathrm{~g}^{-1}$ with $90 \%$ capacity retention after 1,000 cycles and has a low electrode swelling of $17.8 \%$ at a high areal capacity of $5.1 \mathrm{mAh} \mathrm{cm}^{-2}$. The full cell with the prelithiated silicon anode and $\mathrm{Li}\left(\mathrm{Ni}_{1 / 3} \mathrm{Co}_{1 / 3} \mathrm{Mn}_{1 / 3}\right) \mathrm{O}_{2}$ cathode boasts a high energy density of $502 \mathrm{Wh} \mathrm{Kg}^{-1}$ and $84 \%$ capacity retention after 400 cycles. This work provides insights into the rational design of alloy anodes for high-energy batteries.

\footnotetext{
${ }^{1}$ The State Key Laboratory of Refractories and Metallurgy and Institute of Advanced Materials and Nanotechnology, Wuhan University of Science and Technology, 430081 Wuhan, China. ${ }^{2}$ Wuhan National Laboratory for Optoelectronics (WNLO), Huazhong University of Science and Technology, 430074 Wuhan, China. ${ }^{3}$ Department of Physics and Department of Materials Science and Engineering, City University of Hong Kong, Tat Chee Avenue, Kowloon 999077 Hong Kong, China. ${ }^{4}$ Department of Materials Science and Engineering, College of Materials, Xiamen University, 361005 Xiamen, Fujian, China. These authors contribute equally: Weili An, Biao Gao. Correspondence and requests for materials should be addressed to Q.Z. (email: zhangqiaobao@xmu. edu.cn) or to K.H. (email: kfhuo@hust.edu.cn)
} 
西 ast development of portable electronic devices and electric vehicles requires lithium-ion batteries (LIBs) with higher specific power/energy, longer cycle life, and competitive $\operatorname{costs}^{1,2}$. Silicon $(\mathrm{Si})$ has been identified as one of the promising anode materials for next-generation high-energy density LIBs because of its large theoretical specific capacity of $3579 \mathrm{mAh} \mathrm{g}^{-1}$ $\left(\mathrm{Li}_{15} \mathrm{Si}_{4}\right)^{3-5}$. However, $\mathrm{Si}$ suffers from a large volume change ( $>300 \%)$ during lithiation and delithiation causing mechanical pulverization of the particles, loss of inter-particles electrical contact, and continuous formation of the solid-electrolyte interface (SEI), consequently resulting in rapid capacity fading and deteriorated battery performance ${ }^{5-11}$.

Progress has been made to address particle pulverization by decreasing the size to the critical nanosize ${ }^{10}$. Si nanostructures such as nanoparticles ${ }^{12}$, nanowires ${ }^{13}$, nanotubes ${ }^{9}$, as well as nano-Si/carbon hybrids $s^{6,14}$ have been developed as anode materials and enhanced cycle life compared to the bulk counterparts have been demonstrated. However, scalable synthesis of nanostructured $\mathrm{Si}$ with a large tap density, high initial Coulombic efficiency (ICE), and long cycle stability at a high mass loading remains a challenge ${ }^{5,10}$. Nanostructured Si has a large surface area, which increases the electrode/electrolyte interfacial area giving rise to low ICE and the small tap density causes a low volumetric energy density. To improve the tap density and ICE without structural pulverization during lithiation/delithiation, microscale or porous $\mathrm{Si}$ particles assembled from nanoscale building blocks have been proposed as anodes in LIBs ${ }^{11,15-20}$. For example, Cui et $\mathrm{al}^{20}$. prepared yolk-like nanoscale Si/C assembled microscale pomegranate-like particles, which had a tap density of $0.53 \mathrm{~g} \mathrm{~cm}^{-3}$ and $97 \%$ capacity retention after 1000 cycles. Park et $\mathrm{al}^{16}$. prepared microscale porous $\mathrm{Si}$ by electroless metal deposition and chemical etching and the materials had a high capacity of $2050 \mathrm{mAh} \mathrm{g}^{-1}$ at $400 \mathrm{~mA} \mathrm{~g}^{-1}$. However, fabrication of these microscale $\mathrm{Si}$ or $\mathrm{Si} / \mathrm{C}$ materials tends to be costly and is not yet scalable due to the complex synthesis. The tap density and electrochemical cyclability are still unsatisfactory from the commercial standpoint ${ }^{21}$. More importantly, large thickness swelling of the $\mathrm{Si}$ anodes presents the most critical challenge hampering practical implementation in high-energy full cells ${ }^{22}$ but this issue is often ignored in $\mathrm{Si}$ anode research. The large electrode swelling in thickness during lithiation in LIBs decreases the volumetric energy density and undermines cycling performance and unsafety $^{23}$. To address these limitations, rational design of $\mathrm{Si}$ anode materials with a large tap density, minimal electrode thickness swelling, and large areal capacity $\left(>3.0 \mathrm{mAh} \mathrm{cm}^{-2}\right.$ for commercial $\mathrm{LIBs}^{24}$ ) together with a cost-effective and scalable preparation method are highly desirable but still very challenging.

Herein, we report an ant-nest-like microscale porous $\mathrm{Si}$ (AMPSi) for high-performance anodes in LIBs. The AMPSi is produced via a low-cost and scalable top-down approach by thermal nitridation of the $\mathrm{Mg}$-Si alloy in nitrogen $\left(\mathrm{N}_{2}\right)$ followed by the removal of the $\mathrm{Mg}_{3} \mathrm{~N}_{2}$ by-product in an acidic solution (schematically shown in Fig. 1a). The synchrotron radiation tomographic reconstruction images reveal that the AMPSi has 3D interconnected Si nanoligaments and bicontinuous nanoporous network resembling the natural ant nest (Fig. 1b). In situ transmission electron microscopy (TEM) reveals that the Si nanoligaments with widths of several $10 \mathrm{~nm}$ can expand/shrink reversibly during lithiation/delithiation without pulverization and the volume expansion of the Si nanoligaments can be accommodated by the surrounding pores through reversible inward $\mathrm{Li}$ breathing, thereby resulting in negligible particle-level outward expansion as schematically shown in Fig. 1c. The AMPSi integrates the intrinsic merits of nanoscale and microscale $\mathrm{Si}$ with a high tap density of $0.84 \mathrm{~g} \mathrm{~cm}^{-3}$ and small surface area. After coating a 5-8 nm thick carbon layer to improve the conductivity, the anode composed of carbon-coated AMPSi (AMPSi@C) shows a high ICE of $80.3 \%$, gravimetric capacities of 2134, and 1271 $\mathrm{mAh} \mathrm{g}^{-1}$ at 0.1 and $0.5 \mathrm{C}$ rates $\left(1 \mathrm{C}=4200 \mathrm{~mA} \mathrm{~g}^{-1}\right)$, and $90 \%$ capacity retention from the twentieth to thousandth cycles. The AMPSi@C anode with an areal mass loading of $0.8 \mathrm{mg} \mathrm{cm}^{-2}$ delivers a large volumetric capacity of $1712 \mathrm{mAh} \mathrm{cm}^{-3}$ at $0.1 \mathrm{C}$ after 100 cycles, which is the highest reported from $\mathrm{Si}$ anodes so far. Furthermore, the bulk electrode of AMPSi@C with an areal capacity of $5.1 \mathrm{mAh} \mathrm{cm}^{-2}$ exhibits a small electrode swelling of $17.8 \%$, which substantially outperforms most reported $\mathrm{Si}$ anodes ${ }^{11,15,25-27}$. The full cell comprising the prelithiated AMPSi@C anode and commercial $\mathrm{Li}\left(\mathrm{Ni}_{1 / 3} \mathrm{Co}_{1 / 3} \mathrm{Mn}_{1 / 3}\right) \mathrm{O}_{2}$ cathode has a high-energy density of $502 \mathrm{Wh} \mathrm{Kg}^{-1}$ and long-life cycle stability with $84 \%$ capacity retention for over 400 cycles. The economic and scalable top-down fabrication method, rational bulk nanoporous structure design, as well as superior electrochemical properties can be extended to other types of electrodes that tend to undergo large volume expansion in high-energy batteries.

\section{Results}

Synthesis and characterization of AMPSi and AMPSi@C. As shown in Fig. 1a, fabrication of AMPSi commences with $\mathrm{Mg}_{2} \mathrm{Si}$

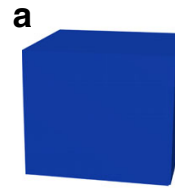
$\mathrm{Mg}_{2} \mathrm{Si}$

b

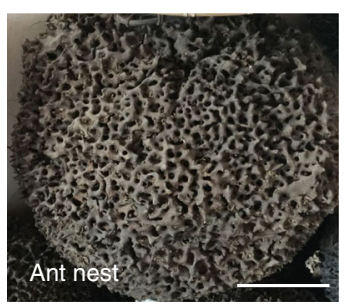

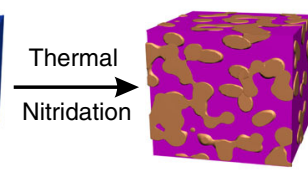

AMPSi $/ \mathrm{Mg}_{3} \mathrm{~N}_{2}$

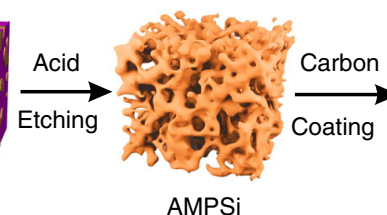

AMPSi

C

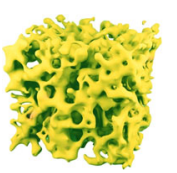

Nanopore Si framework

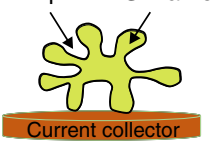

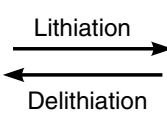

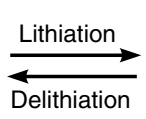

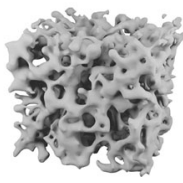

AMPSi@C

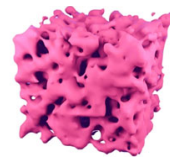

Lithiated S

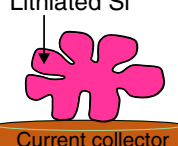

Fig. 1 Design and schematic showing the synthesis method of AMPSi. a Schematic showing the preparation of AMPSi and AMPSi@C. b Photograph of an ant nest (scale bar $=20 \mathrm{~cm}$ ). c Schematic illustrating the lithiation/delithiation process of the ant-nest-like microscale porous Si particles showing inward volume expansion and stable Si framework retention during cycling 
a

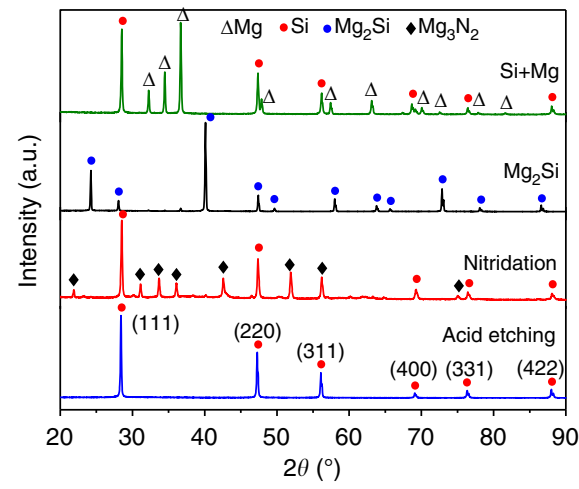

C

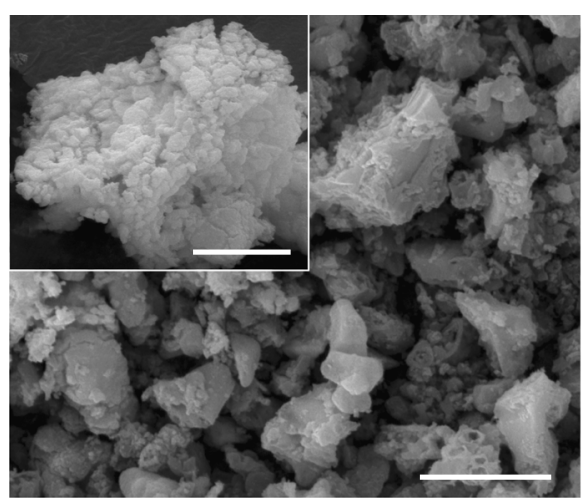

b

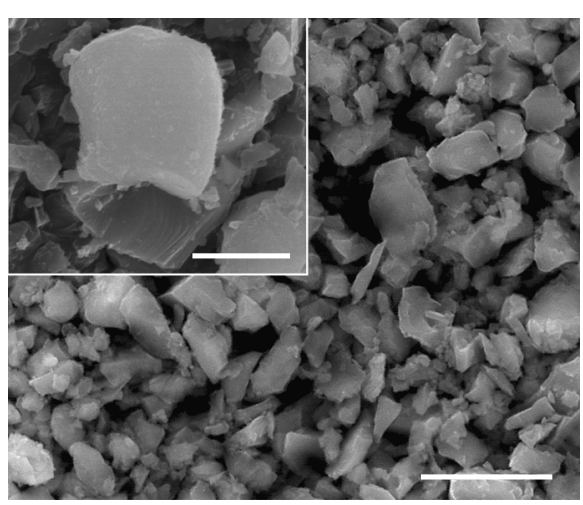

\section{d}

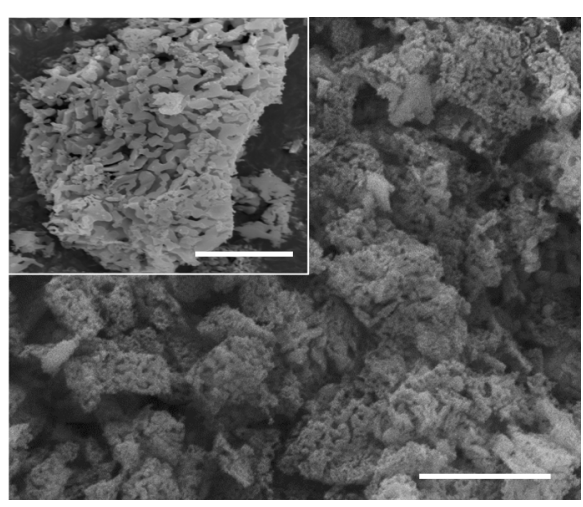

e

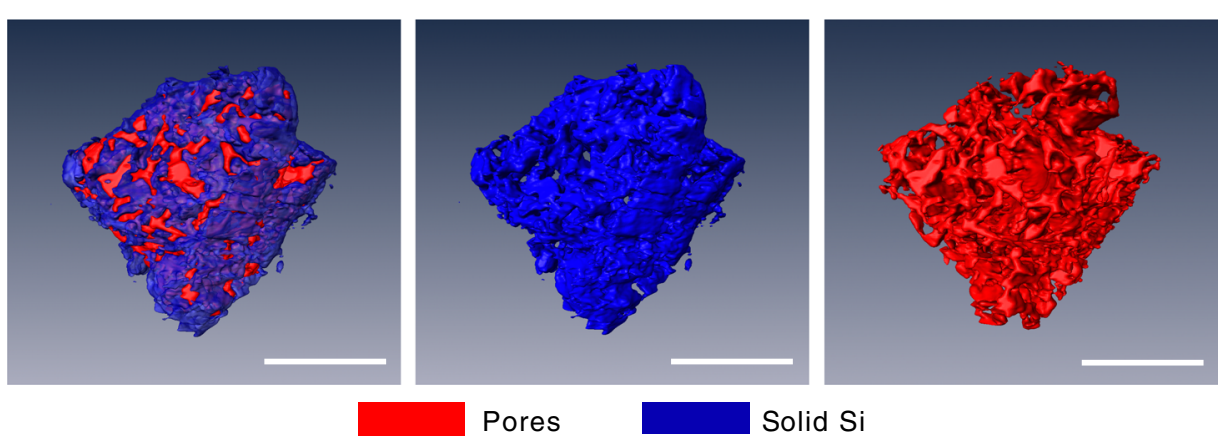

Fig. 2 Morphological and structural characterization. a XRD patterns of the products at different steps during preparation. SEM images of $\mathbf{b}$ pristine $\mathrm{Mg}_{2} \mathrm{Si}$ particles, c nitrided $\mathrm{Mg}_{2} \mathrm{Si}$ particles, and $\mathbf{d}$ AMPSi (scale bar for $\mathbf{b}, \mathbf{c}$, and $\mathbf{d}=3 \mu \mathrm{m}$ and scale bar for the insets $=2 \mu \mathrm{m}$ ). e Synchrotron radiation tomographic 3D reconstruction images of the AMPSi (scale bar $=3 \mu \mathrm{m}$ )

powders commercially available or synthesis from $\mathrm{Mg}$ and metallurgical Si. Here the crystalline 3-5 $\mu \mathrm{m} \mathrm{Mg} \mathrm{Mg}_{2} \mathrm{Si}$ particles are prepared by alloying the bulk metallurgical $\mathrm{Si}$ and $\mathrm{Mg}$ at $550{ }^{\circ} \mathrm{C}$ and then the as-obtained $\mathrm{Mg}_{2} \mathrm{Si}$ particles are nitrided under $\mathrm{N}_{2}$ at $750{ }^{\circ} \mathrm{C}$. During this process, $\mathrm{Mg}$ in $\mathrm{Mg}_{2} \mathrm{Si}$ reacts with $\mathrm{N}_{2}$ to produce $\mathrm{Mg}_{3} \mathrm{~N}_{2}$ while $\mathrm{Si}$ is separated forming the $\mathrm{Mg}_{3} \mathrm{~N}_{2} / \mathrm{Si}$ composite $\left(3 \mathrm{Mg}_{2} \mathrm{Si}(\mathrm{s})+2 \mathrm{~N}_{2}(\mathrm{~g}) \rightarrow 3 \mathrm{Si}(\mathrm{s})+2 \mathrm{Mg}_{3} \mathrm{~N}_{2}(\mathrm{~s})\right)$. The $\mathrm{X}$-ray diffraction (XRD) patterns in Fig. 2a exhibit peaks from $\mathrm{Mg}_{3} \mathrm{~N}_{2}$ (JCPDS No. 73-1070) and Si (JCPDS No. 27-1402), while the peaks associated with the $\mathrm{Mg}_{2} \mathrm{Si}$ phase (JCPDS No. 35-0773) disappear. Compared to pristine $\mathrm{Mg}_{2} \mathrm{Si}$ particles (Fig. 2b), the nitridated $\mathrm{Mg}_{2} \mathrm{Si}$ particles become coarse (Fig. 2c) and the highangle annular dark-field (HAADF) scanning transmission electron microscopy (STEM) and TEM images reveal a loose connecting framework (Supplementary Fig. 1a, b). High-resolution TEM (HR-TEM) (Supplementary Fig. 1c) discloses that the single-crystal $\mathrm{Mg}_{3} \mathrm{~N}_{2}$ and $\mathrm{Si}$ are closely connected forming the $\mathrm{Mg}_{3} \mathrm{~N}_{2} / \mathrm{Si}$ heterostructure. Energy-dispersive X-ray spectroscopy (EDS) mapping (Supplementary Fig. 1d-g) shows uniform distributions of $\mathrm{Si}, \mathrm{Mg}$, and $\mathrm{N}$. After removing $\mathrm{Mg}_{3} \mathrm{~N}_{2}$ in diluted hydrochloric acid, the bulk porous Si particles (Fig. 2d) are obtained. The size of the synthesized AMPSi is measured by a laser particle size analyzer (Mastersizer 2000) and the average diameter $\left(D_{50}\right)$ is $3 \pm 0.2 \mu \mathrm{m}$ (Supplementary Fig. 2a). No $\mathrm{Mg}$ signal is detected from AMPSi by X-ray photoelectron spectroscopy (XPS) indicating complete removal of Mg (Supplementary Fig. 3a, b). The Si 2p XPS spectra in Supplementary Fig. 3c, d show two peaks corresponding to $\mathrm{Si} 2 \mathrm{p} 1 / 2$ and $\mathrm{Si} 2 \mathrm{p} 3 / 2$ of elemental $\mathrm{Si}\left(\mathrm{Si}^{0}\right)$ at binding energies of 98.8 and $99.4 \mathrm{eV}$, and the weak ones at 102.2 and $102.8 \mathrm{eV}$ are associated with $\mathrm{SiO}_{x}$ formed by native oxidation after synthesis ${ }^{13-15}$. The oxygen content in AMPSi is about $6.7 \%$ (wt.). The magnified scanning electron microscopy (SEM) image in the inset of Fig. $2 \mathrm{~d}$ shows that the porous Si particle consists of interconnected nanoligaments and $3 \mathrm{D}$ bicontinuous nanopores resembling the natural ant nest (Fig. 1b). The microstructure of AMPSi is further analyzed by TEM as shown in Supplementary Fig 2b, c. The Si ligaments with a size of $30-50 \mathrm{~nm}$ are interconnected and surrounded by the 
a

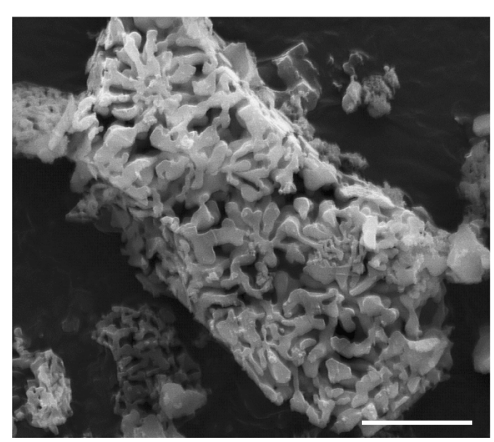

b
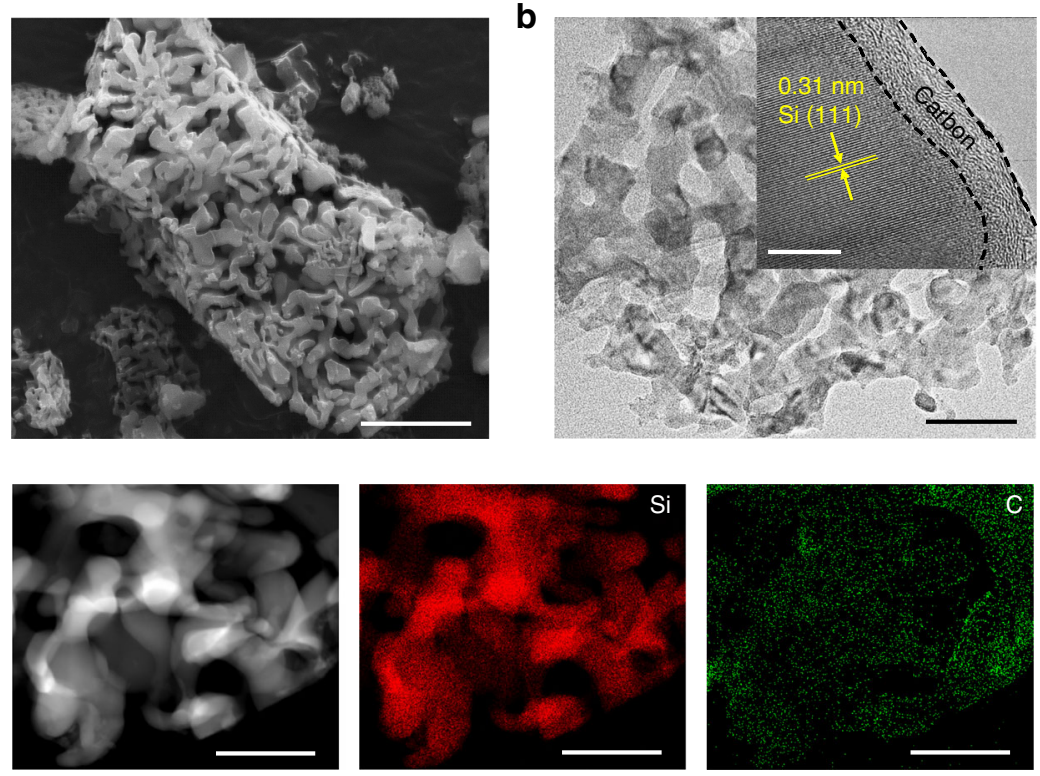

d

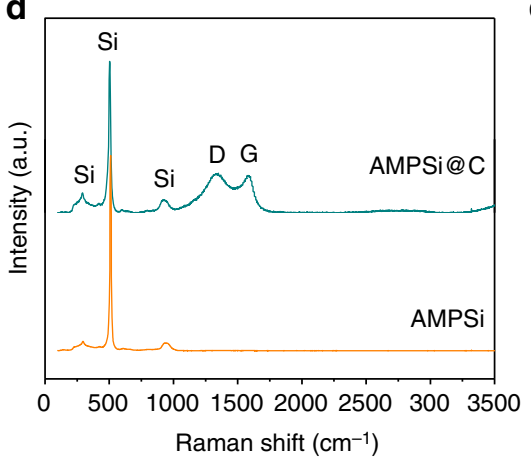

e $1 . 2 \longdiv { \text { Our work } }$

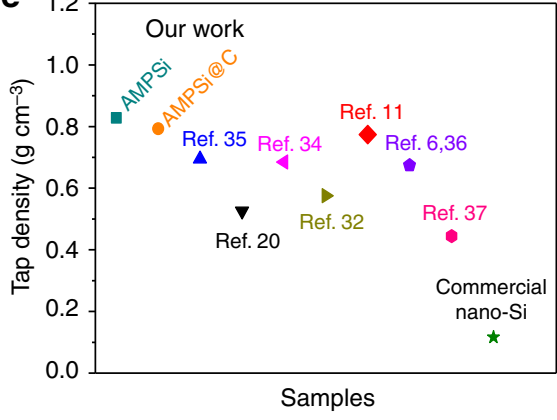

Fig. 3 Characterization of AMPSi@C. a SEM image of AMPSi@C (scale bar=2 $\mu \mathrm{m}$ ). b TEM image of AMPSi@C (scale bar=100 nm).The inset (scale bar $=10 \mathrm{~nm}$ ) is the HR-TEM image showing that the $5-8 \mathrm{~nm}$ thickness amorphous $C$ shell is coated on the Si nanoligaments and the lattice distance of 0.31 $\mathrm{nm}$ corresponds to the $d$-spacing of the (111) planes of crystalline Si (111). c EDS maps of the Si frameworks in AMPSi@C with red and green corresponding to Si and C, respectively (scale bar for $\mathbf{c}=200 \mathrm{~nm}$ ). d Raman scattering spectra of AMPSi and AMPSi@C. e Comparison of the tap densities between our Si anodes and other Si-based anode materials (see Supplementary Table 1)

bicontinuous nanopores forming an ant-nest-like framework. The synchrotron radiation tomographic images (Fig. 2e) further confirm the $3 \mathrm{D}$ continuous nanopore structure and interconnected Si nanoligaments. This unique ant-nest-like material are fundamentally different from previously reported $\mathrm{Si} / \mathrm{C}$ composite secondary particles ${ }^{11,15-20}$. HR-TEM and selected-area electron diffraction (SAED) reveal that AMPSi is composed of many crystalline grains of Si (Supplementary Fig. 4). The AMPSi has a high tap density of $0.84 \mathrm{~g} \mathrm{~cm}^{-3}$, which is larger than that of previously reported nanostructured $\mathrm{Si}$ and microscale $\mathrm{Si}^{6,11,14,15,20,25-27}$.

Since the well-organized pores are continuous and most of the pores are larger than $50 \mathrm{~nm}$, mercury intrusion porosimetry is employed to examine the pores larger than $50 \mathrm{~nm}$ and nitrogen adsorption-desorption isotherms are obtained to assess the mesopores. Brunauer-Emmett-Teller (BET) analysis reveals that the AMPSi has a small specific surface area of $12.6 \mathrm{~m}^{2} \mathrm{~g}^{-1}$ due to the space-efficient packing of AMPSi (Supplementary Fig. 5a, b). The porosity of AMPSi is measured to be $64.3 \%$ that is close to the theoretical value of $68.6 \%$ assuming that the sample undergoes no macroscopic volume change during dealloying $\mathrm{Mg}$ in $\mathrm{Mg}_{2} \mathrm{Si}^{17}$. As schematically shown in Fig. 1c, the high porosity of AMPSi allows inward expansion of the $3 \mathrm{D}$ interconnected Si nanoligaments during cycling consequently, leading to high structural stability and negligible particle-level outward expansion.

To improve the electrical conductivity, a thin C layer is coated on AMPSi by dopamine self-polymerization followed by thermal carbonization, as schematically shown in Fig. 1a. Dopamine is a widely used carbon precursor for C coatings. It can selfpolymerize into polydopamine (PDA) coatings on the surface of $\mathrm{Si}$ with strong adhesion and so the thin and homogeneous carbon shell on Si can be achieved after thermal carbonization. The SEM and TEM images (Fig. 3a, b) disclose that the AMPSi@C retains the 3D ant-nest-like porous structure of the pristine AMPSi and Supplementary Fig. 5b shows that the pore size decreases slightly after $\mathrm{C}$ coating. To confirm the uniform carbon coating, HR-TEM is performed on AMPSi@C at different regions. The HR-TEM images at different regions (inset in Fig. 3b and Supplementary Fig. $6 \mathrm{a}, \mathrm{b}$ ) suggest that the $\mathrm{C}$ shell having a thickness of 5-8 nm is amorphous and the lattice distance of 0.31 nm corresponds to the $d$-spacing of the (111) planes of crystalline $\mathrm{Si}^{25,28}$. EDS mapping (Fig. $3 \mathrm{c}$ and Supplementary Fig. $6 \mathrm{c}$ ) further confirms that $\mathrm{C}$ is uniformly coated on the surface of AMPSi. The Fourier transform infrared (FTIR) spectroscopy spectra of AMPSi and AMPSi@C are depicted in Supplementary Fig. 7. The bands at 1060 and $1620 \mathrm{~cm}^{-1}$ correspond to the characteristic vibrations of Si. Compared to AMPSi, the band of AMPSi@C at $1060 \mathrm{~cm}^{-1}$ 

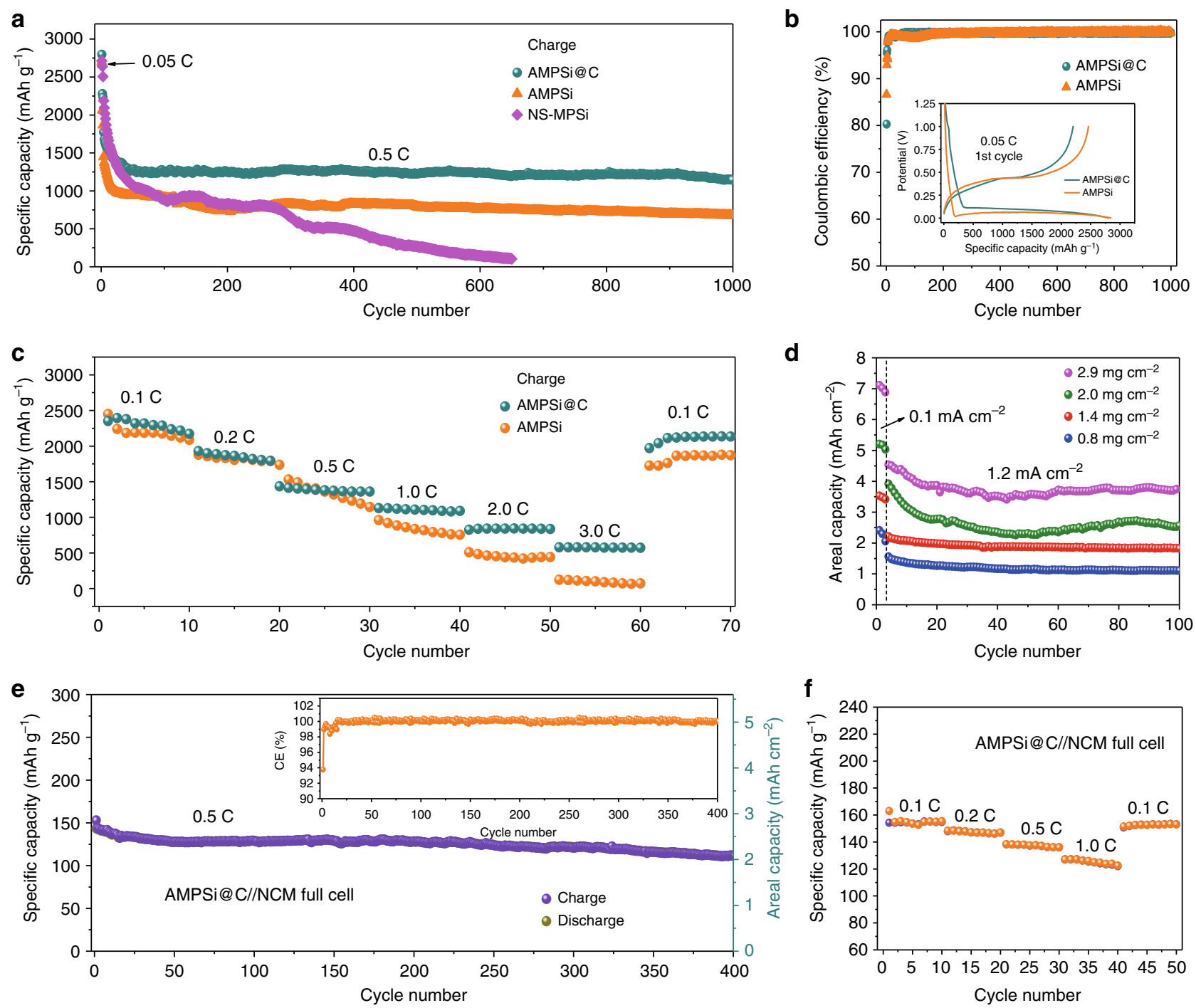

Fig. 4 Electrochemical characterization of anodes in half-cell or full-cell configurations. a Long cycling test of AMPSi@C at 0.5C after the activation process in the first three circles at $0.05 \mathrm{C}\left(1 \mathrm{C}=4.2 \mathrm{~A} \mathrm{~g}^{-1}\right)$ in the half-cell with areal mass loading of $0.8 \mathrm{mg} \mathrm{cm}^{-2}$. $\mathbf{b}$ Comparison of the CE between AMPSi and AMPSi@C in the half-cell configuration with the inset being the corresponding voltage profiles. c Rate performance of AMPSi@C and AMPSi at various current densities from 0.1 to 3 C. d Areal capacities vs. cycling number of the AMPSi@C anodes with different mass loadings at a current density of 1.2 mA $\mathrm{cm}^{-2}$ (the initial three cycles are carried out at $0.1 \mathrm{~mA} \mathrm{~cm}^{-2}$ ). e Full-cell charge at $0.5 \mathrm{C}\left(1 \mathrm{C}=160 \mathrm{~mA} \mathrm{~g}^{-1}\right)$ with prelithiated AMPSi@C anode and a Li $\left(\mathrm{Ni}_{1 / 3} \mathrm{Co}_{1 / 3} \mathrm{Mn}_{1 / 3}\right) \mathrm{O}_{2}$ cathode. The inset showing the corresponding CE. $\mathbf{f}$ Rate performance of the full cell. All the specific capacity values in the half-cell are based on the total mass of AMPSi and $\mathrm{C}$ shell, unless otherwise stated

is split into two peaks at 1240 and $1090 \mathrm{~cm}^{-1}$ suggesting robust bonding between Si and coated carbon shell in AMPSi@C ${ }^{18}$.

The Raman scattering spectrum (Fig. 3d) of AMPSi shows a sharp peak at $511 \mathrm{~cm}^{-1}$ and two weak peaks at 299 and $925 \mathrm{~cm}^{-1}$, corresponding to the characteristic peaks of crystalline nanoscale $\mathrm{Si}^{18,29,30}$. The three peaks corresponding to $\mathrm{Si}$ are still clearly visible from AMPSi@C. However, the strong peak blue-shifts to $504 \mathrm{~cm}^{-1}$ possibly due to confinement effect caused by the carbon coating and strong bonding between the coated carbon and $\mathrm{Si}^{4}$. The two peaks at 1347 and $1581 \mathrm{~cm}^{-1}$ are attributed to the vibration modes of disordered graphite ( $\mathrm{D}$ band) and $\mathrm{E}_{2 \mathrm{~g}}$ of crystalline graphite ( $\mathrm{G}$ band) and the large $\mathrm{I}_{\mathrm{D}} / \mathrm{I}_{\mathrm{G}}$ ratio (1.14) reflects the low graphitic degree in the carbon coating consistent with XRD (Supplementary Fig. 8) and HR-TEM results. The thermogravimetric analysis shows that the $\mathrm{C}$ content in AMPSi@C is 8.5 wt\% (Supplementary Fig. 9). The strong bonding between carbon and Si improves the cycle stability and stabilizes the SEI to enhance the CE during the charging/discharging cycles.
The tap density of AMPSi@C is measured to be $0.80 \mathrm{~g} \mathrm{~cm}^{-3}$ and is slightly less than that of pristine AMPSi of $0.84 \mathrm{~g} \mathrm{~cm}^{-3}$ due to the presence of amorphous $\mathrm{C}$ coating. However, it is still bigger than those of commercial nano-Si, microscale $\mathrm{Si} / \mathrm{C}$, and porous Si/C (Fig. 3e and Supplementary Table 1$)^{6,11,20,31-37}$ thus enabling a bigger volumetric energy density and thinner electrode thickness for the same mass loading in the practical cells.

Electrochemical performance of AMPSi and AMPSi@C. The electrochemical performance of the AMPSi and AMPSi@C electrodes is evaluated using half-cell and full-cell configurations, respectively. For comparison, nanoparticles assembled with 3D mesoporous Si (NS-MPSi) are also prepared by thermal distillation of $\mathrm{Mg}$ in $\mathrm{Mg}_{2} \mathrm{Si}$ in vacuum ${ }^{38}$. The as-prepared NS-MPSi particles are composed of $20-40 \mathrm{~nm}$ primary particles with a specific surface area of $120 \mathrm{~m}^{2} \mathrm{~g}^{-1}$ (Supplementary Fig. 10). The electrolyte is $1.0 \mathrm{M} \mathrm{LiPF}$ in $1: 1 \mathrm{v} / \mathrm{v}$ ethylene carbonate/diethyl 
carbonate with 6 vol \% vinylene carbonate (VC) as the additive. $\mathrm{VC}$ is widely used as an electrolyte additive as it can boost the formation of a smooth and stable SEI on Si-based anodes ${ }^{39}$. All the specific capacity values shown in this paper are based on the total mass of AMPSi@C, unless otherwise stated.

The delithiation capacities of AMPSi, AMPSi@C, and NS-MPSi versus cycle number are presented in Fig. 4a. After the three-cycle activation step at $\mathrm{C} / 20$, the capacity of the AMPSi electrode is maintained at above $679 \mathrm{mAhg}^{-1}$ at $0.5 \mathrm{C}$ with good cycle stability for over 1000 cycles. Under similar conditions, the NSMPSi electrode shows rapid capacity decay from $2712 \mathrm{mAh} \mathrm{g}^{-1}$ in the initial cycle to below $100 \mathrm{mAh} \mathrm{g}^{-1}$ after 650 cycles mainly due to the electrode cracking and structural destruction of NSMPSi during cycling (Supplementary Fig. 11). Compared to AMPSi,AMPSi@C shows a larger reversible capacity of 1271 mAh $g^{-1}$ with $90 \%$ capacity retention from the twentieth to thousandth cycles (Fig. 4a). The large capacity decay during the first 20 cycles is attributed to the increased current density from 0.05 to $0.5 \mathrm{C}$ and continuous formation of SEI due to the slow penetration of the viscous organic electrolyte into the continuous porous structure in AMPSi@C as a result of strong capillary effects, volume expansion of $\mathrm{Si}$, and low crystalline carbon coating. Actually, capacity decay during the first several and even tens of cycles have been observed from $\mathrm{Si}$ and other anode materials $9,20,32,33$. The dQ/dV curve of AMPSi@C is presented in Supplementary Fig. 12 and the anodic and cathodic peaks overlap after 20 cycles suggesting high cycle reversibility. At a high rate up to 3 C,AMPSi@C electrode still shows a large reversible capacity of $632 \mathrm{mAh} \mathrm{g}^{-1}$ with $0.015 \%$ capacity decay per cycle for over 1000 cycles (Supplementary Fig. 13). Moreover, 72.5\% capacity retention can be achieved after 500 cycles at a higher rate of $5.0 \mathrm{C}$ (Supplementary Fig. 14), which outperforms most previously reported microscale $\mathrm{Si}$ and amorphous-C-coated $\mathrm{Si}$ anodes (Supplementary Tables 1 and 2). The role of Fluoroethylene carbonate (FEC) and VC electrolyte additives is also investigated. Although the AMPSi@C anodes display similar cycle stability for both electrolyte additives, AMPSi@C has a slight larger average CE with VC additive (Supplementary Fig. 15).

Cyclic voltammetry (CV) is performed on AMPSi@C in a potential range of $0.01-1.0 \mathrm{~V}$ versus $\mathrm{Li} / \mathrm{Li}^{+}$at a scanning rate of $0.1 \mathrm{mV} \mathrm{s}^{-1}$ as shown in Supplementary Fig. 16a. The broad cathodic peak at $\sim 0.16 \mathrm{~V}$ is ascribed to the formation of $\mathrm{Li}_{x} \mathrm{Si}$ and the anodic peaks at 0.40 and $0.53 \mathrm{~V}$ are characteristic of the $\mathrm{Li}$ desertion process from $\mathrm{Li}_{x} \mathrm{Si}$ to amorphous $\mathrm{Si}$. The chemical states of the cycled electrode are determined by XPS. The fine XPS Si $2 p$ results of the lithiated $(0.01 \mathrm{~V})$ and delithiated $(0.40$ and $0.53 \mathrm{~V})$ samples during the first cycle are depicted in Supplementary Fig. 17. The pristine AMPSi@C shows two Si peaks at 98.8 and $99.4 \mathrm{eV}$ assigned to Si $2 \mathrm{p} 1 / 2$ and $\mathrm{Si} 2 \mathrm{p} 3 / 2$ of elemental $\mathrm{Si}\left(\mathrm{Si}^{0}\right)$. After full lithiation to $0.01 \mathrm{~V}$, the two Si peaks shift to 97.3 and $97.9 \mathrm{eV}$ due to the alloying reaction to form the $\mathrm{Li}_{x} \mathrm{Si}$ phase. When the electrode is delithiated at $0.40 \mathrm{~V}$, the peaks of $\mathrm{Si}^{0}$ reappear and those corresponding to $\mathrm{Li}_{x} \mathrm{Si}$ shift to high binding energy, suggesting partial $\mathrm{Li}$-ion desertion from the $\mathrm{Li}_{x} \mathrm{Si}$ alloy. At a larger delithiation voltage of $0.53 \mathrm{~V}$, stronger peaks of $\mathrm{Si}^{0}$ are observed in line with the $\mathrm{Si}$ binding energy in $\mathrm{Li}_{x} \mathrm{Si}$ shifting to higher energy, meaning that the decreased $\mathrm{Li}$ content in $\mathrm{Li}_{x} \mathrm{Si}$ stems from more Li-ion desertion from the $\mathrm{Li}_{x} \mathrm{Si}$ alloy. The ex situ XPS results agree well with the CV data confirming the alloying/ dealloying reactions of AMPSi@C during lithiation/delithiation. The peak intensity in the CV curves of AMPSi and AMPSi@C (Supplementary Fig. 16a, b) increases initially with cycling possibly due to gradual activation of the electrodes ${ }^{20}$. After several cycles, these peaks overlap suggesting high reversibility and stability. The AMPSi@C electrode exhibits higher peak currents in comparison with the AMPSi electrode implying a largely enhanced capacity. Moreover, the anodic peaks of the AMPSi@C electrode shift to higher voltage while the cathodic peaks shift to a lower voltage. The improved capacity and smaller voltage separation (Supplementary Fig. 16a, b) stem mainly from the higher $\mathrm{Si}$ electrochemical utilization ratio and enhanced electrical conductivity of AMPSi@C, which is further confirmed by electrochemical impede spectroscopy as shown in Supplementary Fig. 18a. The Nyquist plots of the AMPSi and AMPSi@C and corresponding equivalent circuit are depicted in Supplementary Fig. 18. The two semicircles in the high-frequency region represent the resistance of the SEI film $\left(\mathrm{R}_{s f}\right)$ and charge transfer resistance $\left(\mathrm{R}_{c t}\right)$ and the straight lines in the low-frequency region correspond to diffusion of lithium ions $\left(Z_{w}\right) . \mathrm{R}_{s f}$ of AMPSi@C is smaller than that of AMPSi, indicating that the SEI at AMPSi@C is thinner and more stable than that in AMPSi. Moreover, $\mathrm{R}_{c t}$ of AMPSi@C is less than that of AMPSi suggesting smaller resistance due to the high conductivity of the carbon coating. The voltage profiles of the AMPSi and AMPSi@C electrodes during initial cycling are shown in the inset in Fig. 4b, which shows the typical lithiation plateau at around $0.1 \mathrm{~V}$ corresponding to the alloying reaction of $\mathrm{Si}$ with $\mathrm{Li}$ to form $\mathrm{Li}_{x} \mathrm{Si}$ alloy. The initial lithiation capacity of both the AMPSi and AMPSi@C electrodes reaches $2843 \mathrm{mAh} \mathrm{g}^{-1}$ at $0.05 \mathrm{C}$ indicating that most of the $\mathrm{Si}$ in AMPSi and AMPSi@C is active due to the high $\mathrm{Li}^{+}$accessibility of the bulk nanoporous structure. The ICE of AMPSi is $86.6 \%$ (Fig. 4b) and CE reaches $99.9 \%$ after 10 cycles, which are better than those of $\mathrm{Si} / \mathrm{C}$ composites ${ }^{4,10,12}$. The ICE of AMPSi@C is slightly reduced $(80.3 \%)$ possibly because of the formation of more SEI on the surface of the amorphous $\mathrm{C}$ shell as a result of the enlarged surface area of AMPSi@C compared to $\mathrm{AMPSi}^{18}$. Figure $4 \mathrm{c}$ presents the rate performance of the AMPSi and AMPSi@C electrodes. Although both electrodes have similar capacities at 0.1 and 0.2 C,AMPSi@C has much higher capacities at higher rates. Even at a high rate of 3 C, the AMPSi@C electrode has a high capacity of $619 \mathrm{mAh}^{-1}$ that is almost twice that of the AMPSi electrode. Moreover, when the current density is reverted to $0.1 \mathrm{C}$, a reversible capacity of $2134 \mathrm{mAh} \mathrm{g}^{-1}$ is recovered readily implying high structural stability of the AMPSi@C electrode. The tap density of the AMPSi@C electrode is $0.80 \mathrm{mg} \mathrm{cm}^{-3}$ and the volumetric capacity of the AMPSi@C with an areal mass loading of $0.8 \mathrm{mg} \mathrm{cm}^{-2}$ after 100 cycles is measured to be $1712 \mathrm{mAh} \mathrm{cm}^{-3}$ (the lithiated stage) at $0.1 \mathrm{C}$ rate, which is the best value reported from Si-based electrodes so far (Supplementary Fig. 19a) ${ }^{21,40-44}$.

The areal capacities of the AMPSi@C electrodes with different areal mass loadings from 0.8 to $2.9 \mathrm{mg} \mathrm{cm}^{-2}$ are shown in Fig. $4 \mathrm{~d}$. The capacity of the AMPSi@C anode increases linearly with areal mass loading (Supplementary Fig. 19b), indicating that the Si active materials are utilized effectively in spite of the large mass loading. At a high areal mass loading of $2.9 \mathrm{mg} \mathrm{cm}^{-2}$, the areal capacities of AMPSi@C reach $7.1 \mathrm{mAh} \mathrm{cm}^{-2}$ at $0.1 \mathrm{~mA} \mathrm{~cm}^{-2}$ and $3.9 \mathrm{mAh} \mathrm{cm}^{-2}$ at $1.2 \mathrm{~mA} \mathrm{~cm}^{-2}$ after 100 cycles. These values are higher than those of most of the reported $\mathrm{Si}$ anodes $5,10,14,26,45-48$. Generally, when the mass loading of $\mathrm{Si}$ is increased to achieve a larger areal capacity, cycle performance tends to worsen due to the increased serial resistance of the particle-electrolyte interface and electrode-level disintegration ${ }^{49}$. However, the AMPSi@C electrode with a high mass loading still displays good stable cycle stability and excellent rate characteristics (Supplementary Fig. 19c, d) confirming that bulk nanoporous structure of AMPSi@C electrode is favorable to $\mathrm{Li}^{+}$accessibility and electron transport.

To further evaluate the practicality of AMPSi@C in LIBs, a full battery is assembled with the commercial $\mathrm{Li}\left(\mathrm{Ni}_{1 / 3} \mathrm{Co}_{1 / 3} \mathrm{Mn}_{1 / 3}\right) \mathrm{O}_{2}$ (NCM) cathode and prelithiated AMPSi@C anode. The full-cell test is done with an anode limited capacity ratio of 1.1:1 

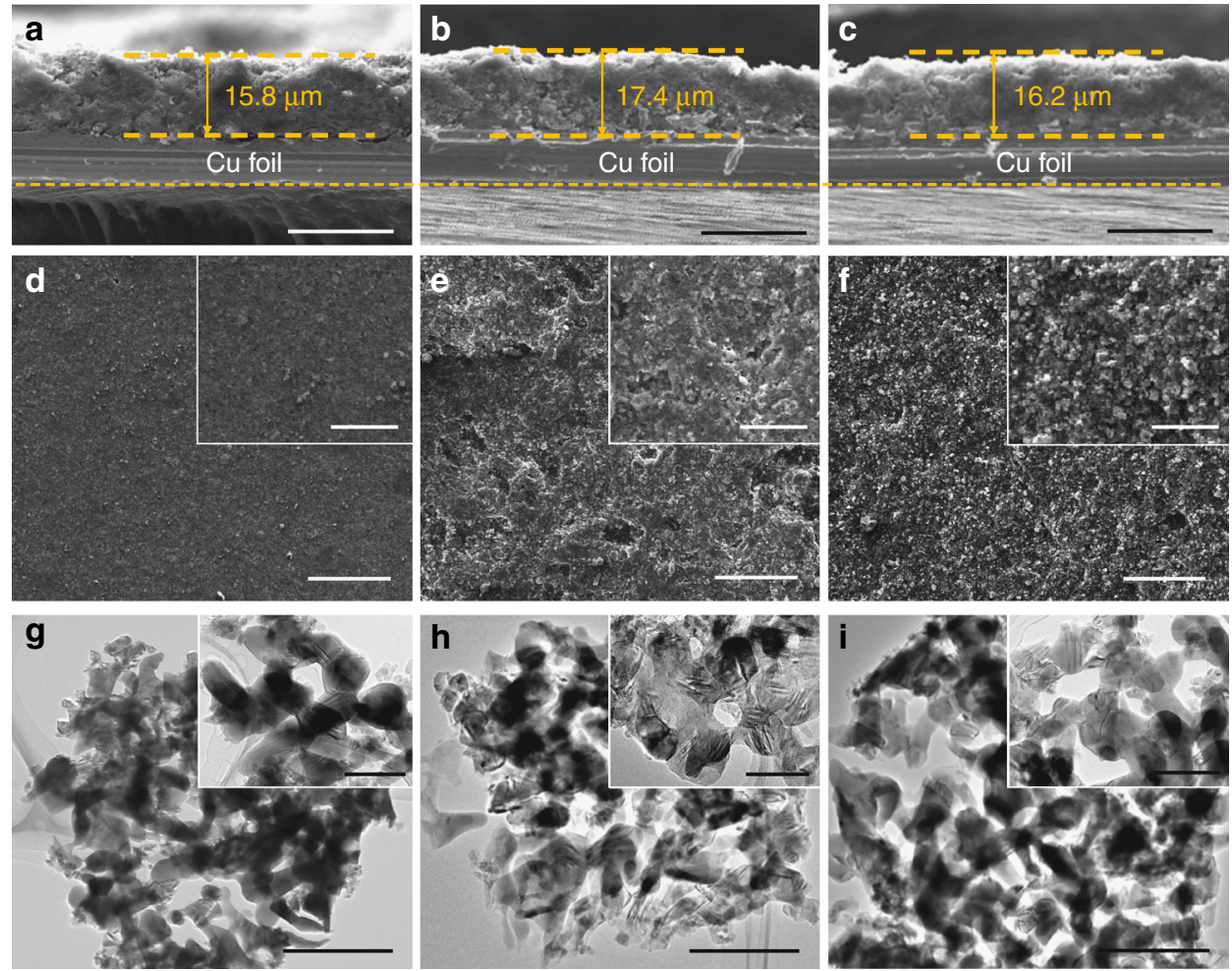

Fig. 5 Electrode swelling measurements of AMPSi@C. Cross-sectional SEM images of the AMPSi@C electrode films a before cycling, b after full lithiation, and $\mathbf{c}$ delithiation, respectively (scale bar for $\mathbf{a}, \mathbf{b}$, and $\mathbf{c}=20 \mu \mathrm{m}$ ). $\mathbf{d}-\mathbf{f}$ Corresponding top-view SEM images (scale bar for $\mathbf{d}-\mathrm{f}=100 \mu \mathrm{m}$ and scale bar for insets = $20 \mu \mathrm{m}$ ). g-i TEM images of AMPSi@C, lithated AMPSi@C and delithiated AMPSi@C (scale bar for $\mathbf{g}-\mathbf{i}=1 \mu \mathrm{m}$ and scale bar for insets=100 nm)
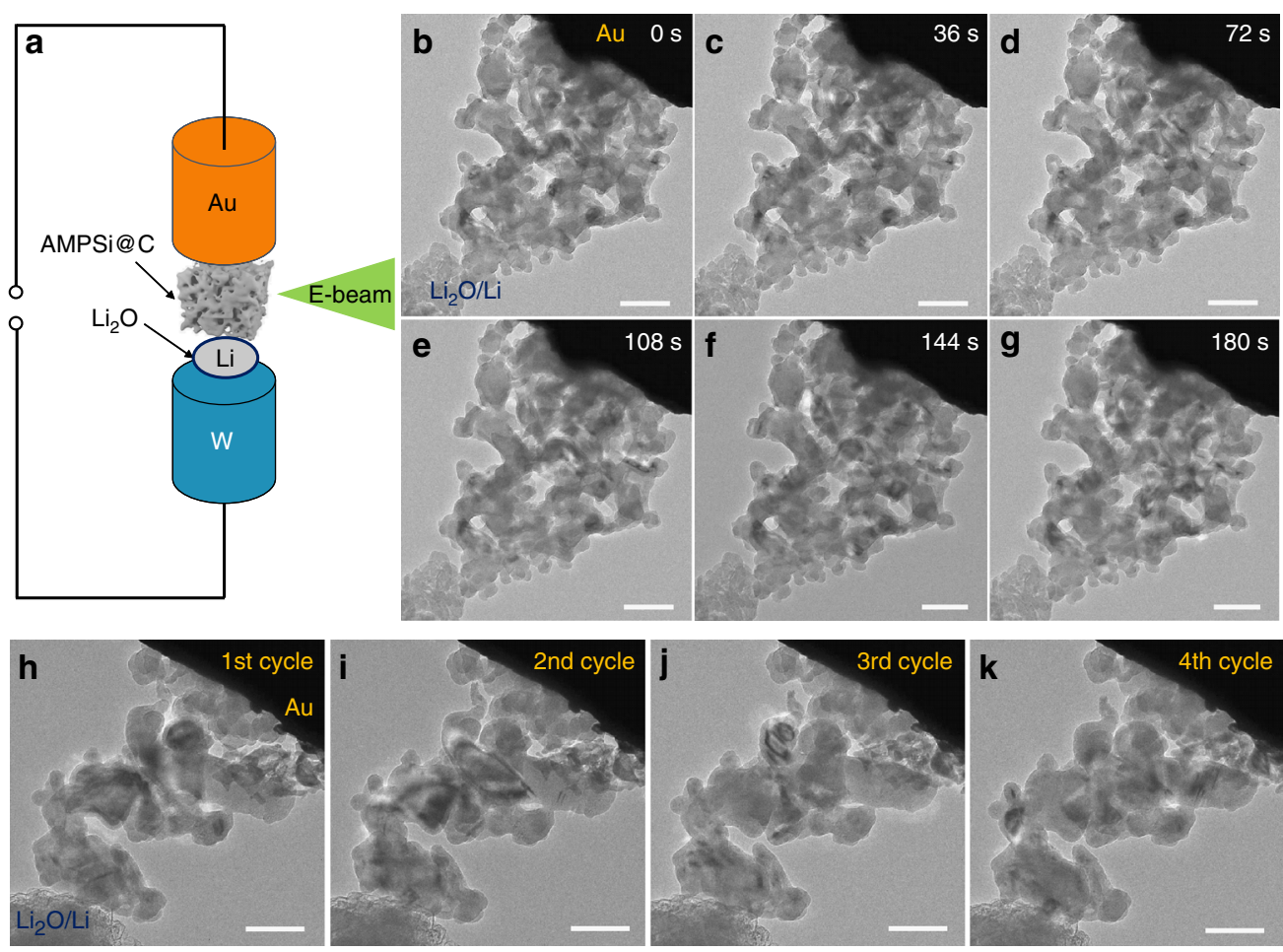

Fig. 6 In situ lithiation/delithiation behavior of AMPSi@C. a Schematic of in situ nanobattery configuration. b-g Time-resolved TEM images depicting the lithiation process of AMPSi@C electrode (Supplementary Movie 1). After full lithiation, AMPSi@C exhibits inward expansion and does not show cracks and pulverization. h-k In situ TEM images of AMPSi@C after different cycles (Supplementary Movie 2) showing a stable structure during repeated cycling. Scale bar for $\mathbf{b}-\mathbf{k}=200 \mathrm{~nm}$ 
considering safety and capacity matching of the full cell during cycling ${ }^{50}$. The prelithiation procedure is conducted in a half-cell by the first discharging process and the working electrode (AMPSi@C) is lithiated to $0.01 \mathrm{~V}$ at a $0.05 \mathrm{C}$ rate by the galvanostatic discharging method (see details in Methods). The typical charging-discharging curves of the AMPSi@C//NCM full cell with a cutoff voltage of $2.80-4.25 \mathrm{~V}$ is shown in Supplementary Fig. 20a and Fig. 4e depicts the cycle stability. The AMPSi@C//NCM full cell delivers a high reversible capacity of $134 \mathrm{mAh} \mathrm{g}^{-1}$ at $0.5 \mathrm{C}\left(1 \mathrm{C}=160 \mathrm{~mA} \mathrm{~g}^{-1}\right.$ based on cathode active material) with capacity retention of $84 \%$ for over 400 cycles. Moreover, the full battery exhibits a high rate capability of 118 $\mathrm{mAh} \mathrm{g}^{-1}$ at $1.0 \mathrm{C}$ (Fig. 4f). The corresponding CE is shown in the inset in Fig. 4e. The ICE of the AMPSi@C//NCM full cell is $94 \%$ and the later CE reaches $99.9 \%$ after 10 cycles (inset of Fig. 4 e). The full cell has an average voltage of $3.75 \mathrm{~V}$ and the discharge capacity is $134 \mathrm{mAh} \mathrm{g}^{-1}$ at $0.5 \mathrm{C}$, thus, the full cycle can deliver a high-energy density of $502 \mathrm{Wh} \mathrm{kg}^{-1}$ outperforming previously reported Si-based full cells $s^{4,46}$ (Supplementary Table 1 and 2). For comparison, we also evaluate the cycling performance of full cells using AMPSi@C anodes without prelithiation (Supplementary Fig. 20b). It shows a lower ICE of $83.1 \%$, lower capacity, and poor cycle stability than the prelithiated AMPSi@C anode, indicating that prelithiation is necessary to enhance the performance of the full cell.

Electrode swelling and in situ lithiation of AMPSi@C. Electrode swelling is a show stopper for commercial implementation of Sibased LIBs but often ignored in Si anode research. Large electrode swelling of $\mathrm{Si}$ anodes undermines the long-term cycling stability and safety. The cross-sectional SEM images show that the pristine AMPSi@C electrode film has an average thickness of $15.8 \mu \mathrm{m}$ (Fig. 5a) and after full lithiation, the electrode thickness increases to $17.4 \mu \mathrm{m}$ (Fig. 5b) with $10.1 \%$ thickness swelling. After full delithiation, the electrode thickness recovers to $16.2 \mu \mathrm{m}$ (Fig. $5 \mathrm{c}$ ), indicating negligible thickness change. The small swelling and negligible thickness fluctuation of the AMPSi@C electrode ensure superior stability and safety in practice. The corresponding topview SEM images reveal that the AMPSi@C electrode shows no observable mechanical damage such as cracking or fracture during cycling (Fig. 5d-f). More importantly, the microstructure of AMPSi@C remains intact even after 1000 cycles, confirming the high structure stability and integrality during cycling as shown by the TEM images (Fig. 5g-i). Electrode thickness swelling of the $\mathrm{Si}$ anodes with different areal capacities of 3.5-7.1 $\mathrm{mAh} \mathrm{cm}^{-2}$ is also assessed (Supplementary Fig. 21). The AMPSi@C electrodes with thicknesses of 25.8, 34.7, and $45.1 \mu \mathrm{m}$ deliver areal capacities of $3.5,5.1$, and $7.1 \mathrm{mAh} \mathrm{cm}^{-2}$. After full lithiation, the electrode thicknesses increase to 29.4, 40.9, and $55.3 \mu \mathrm{m}$, corresponding to $14.0 \%, 17.8 \%$, and $22.6 \%$ electrode swelling, respectively, as shown in Supplementary Fig. 22. These values are much smaller than those of previously reported $\mathrm{Si}$ anodes $^{11,15,25-27,47,48}$ (Supplementary Table 1). The large areal capacity and small electrode thickness swelling suggest promising applications of AMPSi@C in high-energy LIBs.

The structural evolution of AMPSi@C during lithiation is observed by in situ TEM using a nanobattery setup as schematically shown in Fig. 6a. AMPSi@C is attached on a gold tip and then connected to $\mathrm{Li} / \mathrm{Li}_{2} \mathrm{O}$ on a tungsten (W) tip. The asformed thin $\mathrm{Li}_{2} \mathrm{O}$ layer on $\mathrm{Li}$ serves as a solid electrolyte. The AMPSi@C is lithiated when a negative bias $(-3 \mathrm{~V})$ is applied to the W end and the delithiation process of AMPSi@C is realized when applying a positive bias. When the Li source comes in close contact, $\mathrm{Li}$ ions diffuse quickly from the contact point to the AMPSi@C via wave propagation-like motion ${ }^{51}$. The structural changes of AMPSi@C during lithiation is monitored by the timeresolved TEM images in Fig. 6b-g captured from in situ videos (Supplementary Movie 1). As lithiation proceeds, the Si framework maintains its intrinsic structure without any notable particle-level outward expansion (Supplementary Movie 1), which is confirmed by the similar projected area of AMPSi@C during lithiation process. However, the magnified TEM images (Supplementary Fig. 23) of the pristine state, first lithiated state, and forth lithiated state of AMPSi@C demonstrate pore filling (shown in the red region) and at the same time, the particle size increases and shape changes (shown by the blue arrow). To further study the volume change of the electrode materials, snapshots are taken during lithiation by taking in situ TEM video (Supplementary Movie 2) of a representative $\mathrm{Si}$ particle in AMPSi@C at different lithiation time as shown in Supplementary Fig. 24. The size of the partial Si skeleton (shown in red region) is measured to be $105,112,117$, and $125 \mathrm{~nm}$ after lithiation for 3 , 20, 40, and $60 \mathrm{~s}$, respectively. Meanwhile, the pore (shown in yellow region) is filled accordingly. The robust structural stability of AMPSi@C is further confirmed by in situ TEM during fast lithiation/delithiation cycling (Figs. $6 \mathrm{~h}-\mathrm{k}$ and Supplementary Movie 2). As shown in Figs. $6 \mathrm{~h}-\mathrm{k}$, even when a large constant bias of $-6 / 6 \mathrm{~V}$ is applied, AMPSi@C shows inward expansion of Si nano skeleton without any notable structural change during four lithiation/delithiation cycles (Supplementary Movie 2). In situ TEM is also performed on AMPSi@C at a higher negative bias $(-9 \mathrm{~V})$. As shown in Supplementary Movie 3, the AMPSi@C shows a sudden change leading to abrupt inward expansion of the $\mathrm{Si}$ nanoskeleton due to the fast lithiation rate. Nonetheless, the structure of AMPSi@C is sufficiently robust without showing observable mechanical degradation.

The in situ TEM results indicate that AMPSi@C remains stable without cracking and lithiation induced volume expansion of nanoligaments is largely accommodated by the surrounding pores. The inward volume expansion of AMPSi@C enables minimum particle-level outer expansion during lithiation/ delithiation cycling, giving rise to small swelling and excellent cycling performance. Moreover, the outer carbon coating enhances electron/ion transport and acts as a protective layer to stabilize SEI on the AMPSi@C electrode resulting in the excellent electrochemical properties.

\section{Discussion}

A vapor dealloying reaction to produce AMPSi from the $\mathrm{Mg}-\mathrm{Si}$ alloy via a low-cost and scalable top-down approach is designed and described. At $750{ }^{\circ} \mathrm{C}, \mathrm{Mg}$ reacts with $\mathrm{N}_{2}$ to form liquid $\mathrm{Mg}_{3} \mathrm{~N}_{2}{ }^{52}$ and solid $\mathrm{Si}$ is separated producing the $\mathrm{Mg}_{3} \mathrm{~N}_{2} / \mathrm{Si}$ heterostructure. The in situ generated liquid $\mathrm{Mg}_{3} \mathrm{~N}_{2}$ acts as the selftemplate and filler in the $\mathrm{Mg}_{3} \mathrm{~N}_{2} / \mathrm{Si}$ hybrid. After removing $\mathrm{Mg}_{3} \mathrm{~N}_{2}$ in an acidic solution, the bulk Si microparticles are produced, which consist of a bicontinuous porous network and crystalline Si nanoligaments resembling ant nests. The pore size and porosity of AMPSi can be adjusted by varying the Mg concentration in the $\mathrm{Mg}$-Si alloy and nitridation temperature. Moreover, the $\mathrm{MgCl}_{2}$ by-product can be converted into $\mathrm{Mg}$ for recycling. This top-down method is simple and economical and can be scaled up for commercial production. In fact, we can produce $3-5 \mu \mathrm{m}$ AMPSi particles in $110 \mathrm{~g}$ per batch in our laboratory using conventional tube furnaces (Supplementary Fig. 2d).

The superior electrochemical properties of AMPSi@C can be attributed to the ant-nest-like structure, which integrates the intrinsic merits of nanoscale and microscale Si. The 3D bicontinuous nanopores enable fast diffusion of the electrolyte and high $\mathrm{Li}^{+}$accessibility, whereas the interconnected nanoscale $\mathrm{Si}$ 
ligaments prevent pulverization and cracking. The bicontinuous nanoporous network allows inward volume expansion of $\mathrm{Si}$ nanoligaments without obvious particle size change. Our in situ TEM results reveal that the volume change of the Si ligaments is accommodated by the surrounding pores through reversible inward Li breathing without obvious particle size expansion. The as-obtained AMPSi@C has a porosity of 64.3\%. The maximum volume accommodation limitation $(\Delta V)$ of AMPSi@C is calculated to be $280 \%$ according to the equation: $\Delta V=V_{\text {Porosity }} / V_{\mathrm{Si}}+1$ without considering binders and conductive additives ${ }^{17,53}$. Here, $V_{\text {Porosity }}$ is the pore volume and $V_{\mathrm{Si}}$ is the volume of solid $\mathrm{Si}$. The large $\Delta V$ of $280 \%$ gives rise to a lithiation capacity of $\sim 2382 \mathrm{mAh} \mathrm{g}^{-1}$ that is higher than that of AMPSi@C $\left(2134 \mathrm{mAh} \mathrm{g}^{-1}\right.$ at $\left.0.1 \mathrm{C}\right)$ and therefore, in situ TEM demonstrates negligible particle-level outward expansion of AMPSi@C upon lithiation (Supplementary Movie 1-3). The bulk AMPSi@C shows a large tap density and the carbon coating enhances electron/ion transport. Hence, AMPSi@C exhibits enhanced capacity retention and cycling life in comparison with other Si-based anodes. Moreover, inward Li breathing in AMPSi@C gives rise to minimal electrode swelling and large volumetric capacity at the lithiated state. The full cell composed of $\mathrm{Li}\left(\mathrm{Ni}_{1 / 3} \mathrm{Co}_{1 / 3} \mathrm{Mn}_{1 / 3}\right) \mathrm{O}_{2} / /$ AMPSi@C has a high-energy density of $502 \mathrm{Wh} \mathrm{kg}^{-1}$ and superior cycle stability with $84 \%$ capacity retention after 400 cycles. Owing to self-volume expansion effect of AMPSi@C with negligible particle-level outer expansion, low thickness swelling is achieved in spite of a large areal mass loading and electrode thickness (Supplementary Fig. 21).

In summary, a simple, economical, and scalable nitrogen dealloying technique to fabricate ant-nest-like microscale porous $\mathrm{Si}$ from the $\mathrm{Mg}-\mathrm{Si}$ alloy is reported for the first time. The asobtained AMPSi@C has continuous pores and interconnected crystalline Si nanoligaments thereby overcoming technical hurdles which have hampered the use of bulk microscale $\mathrm{Si}$ in highperformance practical anodes in LIBs. The new design of AMPSi@C simultaneously improves the tap density and electrochemical stability to achieve large volumetric capacity and longterm cycling stability for LIBs. In situ TEM reveals the selfvolume inward expansion mechanism of AMPSi@C, which effectively mitigates electrochemically-induced mechanical degradation of the AMPSi@C electrode during cycling and the bulk AMPSi anode shows less than 20\% electrode thickness swelling even at a high areal capacity of $5.1 \mathrm{mAh} \mathrm{cm}^{-2}$. By virtue of these unique structural features, the AMPSi@C electrode shows superior rate capability and long-term cycling stability in full cells with a high-energy density of $502 \mathrm{Wh} \mathrm{Kg}^{-1}$. Our findings offer insights into the rational design of alloy-based materials that normally undergo large volume changes during operation and application for advanced electrochemical energy storage.

\section{Methods}

Synthesis of Mg-Si alloy. The metallurgical Si purchased from Jinzhou Haixin Metal Materials Co., Ltd. was milled to $1-3 \mu \mathrm{m}$ with a sand mill (Shenzhen Sanxing Feirong Machine Co., Ltd) and then $2.8 \mathrm{~g}$ of the milled Si powers were mixed with $5 \mathrm{~g}$ of $\mathrm{Mg}$ powders (200 mesh, Sinopharm Chemical Reagent Co., Ltd) to form $\mathrm{Mg}_{2} \mathrm{Si}$ in a stainless steel reactor heated to $550^{\circ} \mathrm{C}$ for $4 \mathrm{~h}$.

Synthesis of AMPSi and NS-MPSi. The $\mathrm{Mg}_{2} \mathrm{Si}$ powders $(3-5 \mu \mathrm{m})$ were thermally nitrided in $\mathrm{N}_{2}$ at $750^{\circ} \mathrm{C}$. After thermal reaction, the powders were immersed into 1 $\mathrm{M}$ diluted hydrochloric acid to remove $\mathrm{Mg}_{3} \mathrm{~N}_{2}$ and the AMPSi powers were collected by filtration. We also prepared nanoparticles assembled $3 \mathrm{D}$ mesoporous $\mathrm{Si}$ (NS-MPSi) by evaporating $\mathrm{Mg}$ from $\mathrm{Mg}_{2} \mathrm{Si}$ at $900^{\circ} \mathrm{C}$ under vacuum for $6 \mathrm{~h}$ as the control sample.

Synthesis of carbon coating AMPSi (AMPSi@C). $0.4 \mathrm{~g}$ of AMPSi and $0.48 \mathrm{~g}$ of 2-amino-2-hydroxymethylpropane-1,3-diol (Sigma-Aldrich, 98\%) were dispersed in $400 \mathrm{ml}$ of deionized water and $0.6 \mathrm{~g}$ of dopamine hydrochloride (Aladdin, $98 \%$ ) were added under mechanical stirring. The polydopamine-coated AMPSi product was collected by filtration and then heated at $850^{\circ} \mathrm{C}$ for $3 \mathrm{~h} \mathrm{in} \mathrm{Ar} / \mathrm{H}_{2}$. During this process, the polydopamine coating was carbonized into a thin $\mathrm{N}$-doped carbon shell and the final product of AMPSi@C was obtained.

Materials characterization. The morphology and microstructure of the AMPSi and AMPSi@C were characterized by field-emission scanning electron microscopy (FE-SEM, FEI Nano 450), transmission electron microscopy (TEM, FEI Titan 60-300 Cs), and high-resolution TEM (HR-TEM, Tecnai G20). The crystal structure, chemical compositions and chemical bonds of materials were characterized by X-ray diffraction (GAXRD, Philips X'Pert Pro), X-ray photoelectron spectroscopy (XPS, ESCALB MK-II, VG Instruments, UK), energy-dispersive Xray spectroscopy (EDS, Bruker, Super-X), Raman scattering (HB RamLab), and Fourier transform infrared spectroscopy (FTIR, VERTEX 70, Bruker). The surface areas were measured via Brunauer-Emmett-Teller (BET, Micrometrics, ASAP2010) method and the porosity was determined using the mercury porosimeter (Micromeritics, AutoPore V). The 3D structure of AMPSi was obtained by tomographic reconstruction strategy, which was carried out via the total variation based simultaneous algebraic reconstruction technique with synchrotron radiation (National Synchrotron Radiation Laboratory, Hefei, Anhui, China). Thermogravimetry (TG, STA449/6/GNETZSCH) was carried out from 30 to $1000^{\circ} \mathrm{C}$ at a rate of $5^{\circ} \mathrm{C} \mathrm{min}-1$ in air. The tap density was measured on a vibration density tester (Dandong Haoyu, HY-100B).

In situ TEM. The typical nanobattery setup consisted of the working electrode (AMPSi@C), the counter electrode (Li metal), and the solid electrolyte of a naturally grown $\mathrm{Li}_{2} \mathrm{O}$ layer. A gold wire was used to capture the AMPSi@C particle by scratching the AMPSi@C sample, which was then transferred and loaded into the nanofactory TEM-scanning tunneling microscope (STM) specimen holder ${ }^{54}$. A tungsten tip was used to scratch Li metal and inserted into a holder in a glove box. Then, the holder was quickly transferred to the TEM instrument (JEOL-2100) and natural thin $\mathrm{Li}_{2} \mathrm{O}$ layer was formed on the surface of $\mathrm{Li}$ metal due to the native oxidation in air. The $\mathrm{Li}_{2} \mathrm{O}$ layer on the tungsten tip was controlled to contact AMPSi@C to complete the nanobattery construction. The Li ions go through the $\mathrm{Li}_{2} \mathrm{O}$ layer to alloy with $\mathrm{Si}$ at the working electrode under applied voltages of -3 , -6 , and $-9 \mathrm{~V}$.

Electrochemical tests and electrode swelling measurements. The electrodes were fabricated via the mixture of active materials, Super-P carbon black, and sodium alginate in water solution to form a slurry at a mass ratio of 8:1:1. The aqueous slurry was coated on a $\mathrm{Cu}$ foil by an automatic thick film coater (MTI MSK-AFA-III) with mass loadings on the electrode of $0.8-2.9 \mathrm{~m} \mathrm{~cm}^{-2}$. After vacuum drying, the electrode with a diameter of $12 \mathrm{~mm}$ was prepared with a manual rolling machine. The coin cells (CR2016 type) were assembled in a glove box (Vigor SG1200/750TS-C) by using a Celgard 2400 film as separator, Li foil as a counter electrode, and $1 \mathrm{M} \mathrm{LiPF}_{6}$ in a mixture of diethyl carbonate and ethylene carbonate (1:1) with 6 wt.\% VC or FEC additives as the electrolyte. The electrochemical measurements were carried out on the battery tester LANDCT2001A (Wuhan LAND electronics Co., Ltd., China). Cyclic voltammetry (CV) and electrochemical impedance spectroscopy (EIS) were conducted on a CHI750e electrochemical workstation (Shanghai CH Instrument Company, China). The full cells were assembled with prelithiated AMPSi@C as the anode and commercial $\mathrm{Li}\left(\mathrm{Ni}_{1 / 3} \mathrm{Co}_{1 / 3} \mathrm{Mn}_{1 / 3}\right) \mathrm{O}_{2}(\mathrm{NCM})$ as the cathode. The ratio of negative electrode and positive electrode capacity was about 1.1:1. Galvanostatic charging/discharging was carried out to evaluate the electrochemical performance between $2.8 \mathrm{~V}$ and $4.25 \mathrm{~V}$ at $0.5 \mathrm{C}\left(1 \mathrm{C}=160 \mathrm{~mA} \mathrm{~g}^{-1}\right.$ based on the cathode active material). Electrochemical prelithiation of AMPSi@C was conducted on the anode of a coin-like half-cell with AMPSi@C as the working electrode and $\mathrm{Li}$ foil as the counter electrode. The prelithiation process was conducted via the first discharging process and the working electrode (AMPSi@C) was lithiated to $0.01 \mathrm{~V}$ at a $0.05 \mathrm{C}$ rate by a galvanostatic discharging method and this potential was kept for $30 \mathrm{~min}$. After prelithiation, the half-cell of AMPSi@C//Li was disassembled in a glove box and the prelithiated AMPSi@C electrode was taken out quickly, which coupled with the $\mathrm{Li}\left(\mathrm{Ni}_{1 / 3} \mathrm{Co}_{1 / 3} \mathrm{Mn}_{1 / 3}\right) \mathrm{O}_{2}$ cathode to form a full cell.

\section{Data availability}

The data that support the findings of this study are available from the corresponding authors upon reasonable request.

Received: 27 September 2018 Accepted: 15 March 2019 Published online: 29 March 2019

\section{References}

1. Schmuch, R. et al. Performance and cost of materials for lithium-based rechargeable automotive batteries. Nat. Energy 3, 267-278 (2018). 
2. Armand, M. \& Tarascon, J. M. Building better batteries. Nature 451, 652-657 (2008).

3. Hatchard, T. D. et al. In situ XRD and electrochemical study of the reaction of lithium with amorphous silicon. J. Electrochem. Soc. 151, A838-A842 (2004).

4. $\mathrm{Hu}, \mathrm{Y}$. S. et al. Superior storage performance of a $\mathrm{Si}_{\mathrm{SSiO}} / \mathrm{C}$ nanocomposite as anode material for lithium-ion batteries. Angew. Chem. Int. Ed. 47, 1645-1649 (2008).

5. Li, Y. Z. et al. Growth of conformal graphene cages on micrometre-sized silicon particles as stable battery anodes. Nat. Energy 1, 15029 (2016).

6. $\mathrm{Xu}, \mathrm{Q}$. et al. Watermelon-inspired $\mathrm{Si} / \mathrm{C}$ microspheres with hierarchical buffer structures for densely compacted lithium-ion battery anodes. Adv. Energy Mater. 7, 1601481 (2016)

7. Mcdowell, M. T. et al. In situ TEM of two-phase lithiation of amorphous silicon nanospheres. Nano. Lett. 13, 758-764 (2013).

8. Mcdowell, M. T., Lee, S. W., Nix, W. D. \& Cui, Y. 25th anniversary article: understanding the lithiation of silicon and other alloying anodes for lithiumion batteries. Adv. Mater. 25, 4966-4985 (2013).

9. $\mathrm{Wu}, \mathrm{H}$. et al. Stable cycling of double-walled silicon nanotube battery anodes through solid-electrolyte interphase control. Nat. Nanotechnol. 7, 310-315 (2012).

10. Liu, X. H. et al. Size-dependent fracture of silicon nanoparticles during lithiation. ACS Nano 6, 1522-1531 (2012).

11. Yi, R. et al. Micro-sized Si-C composite with interconnected nanoscale building blocks as high-performance anodes for practical application in lithium-ion batteries. Adv. Energy Mater. 3, 295-300 (2013).

12. $\mathrm{Du}, \mathrm{F}$. H. et al. Surface binding of polypyrrole on porous silicon hollow nanospheres for Li-ion battery anodes with high structure stability. $A d v$. Mater. 26, 6145-6150 (2014).

13. Zhou, H. et al. Role of surface functionality in the electrochemical performance of silicon nanowire anodes for rechargeable lithium batteries. ACS Appl. Mater. Interfaces 6, 7607-7610 (2014).

14. Zhang, Y. C. et al. Rice husk-derived hierarchical silicon/nitrogen-doped carbon/carbon nanotube spheres as low-cost and high-capacity anodes for lithium-ion batteries. Nano Energy 25, 120-127 (2016).

15. Chae, S. J. et al. Micron-sized Fe-Cu-Si ternary composite anodes for high energy Li-ion batteries. Energy Environ. Sci. 9, 1251-1257 (2016).

16. Bang, B. M. et al. High-performance macroporous bulk silicon anodes synthesized by template-free chemical etching. Adv. Energy Mater. 2, 878-883 (2012).

17. Wada, T. et al. Bulk-nanoporous-silicon negative electrode with extremely high cyclability for lithium-ion batteries prepared using a top-down process. Nano. Lett. 14, 4505-4510 (2014).

18. Wang, J. et al. Scalable synthesis of defect abundant Si nanorods for highperformance Li-ion battery anodes. ACS Nano 9, 6576-6586 (2015).

19. Chae, S. J. et al. One-to-one comparison of graphite-blended negative electrodes using silicon nanolayer-embedded graphite versus commercial benchmarking materials for high-energy lithium-ion batteries. Adv. Energy Mater. 7, 1700071 (2017).

20. Liu, N. et al. A pomegranate-inspired nanoscale design for large-volumechange lithium battery anodes. Nat. Nanotechnol. 9, 187-192 (2014).

21. Magasinski, A. et al. High-performance lithium-ion anodes using a hierarchical bottom-up approach. Nat. Mater. 9, 353-358 (2010).

22. Freunberger, S. A. True performance metrics in beyond-intercalation batteries. Nat. Energy 2, 17091 (2017)

23. Xiao, X. et al. Regulated breathing effect of silicon negative electrode for dramatically enhanced performance of Li-ion battery. Adv. Funct. Mater. 25, 1426-1433 (2015).

24. Chae, S. et al. Confronting issues of the practical implementation of Si anode in high-energy lithium-ion batteries. Joule 1, 47-60 (2017).

25. Wang, B. et al. Self-template construction of mesoporous silicon submicrocube anode for advanced lithium ion batteries. Energy Storage Mater. 15, A8389-147 (2018).

26. Li, X. L. et al. Mesoporous silicon sponge as an anti-pulverization structure for high-performance lithium-ion battery anodes. Nat. Commun. 5, 4105 (2014).

27. Ngo, D. T. et al. Highly porous coral-like silicon particles synthesized by an ultra-simple thermal-reduction method. J. Mater. Chem. A 6, 2834-2846 (2018).

28. Kim, N., Park, H., Yoon, N. \& Lee, J. K. Zeolite-templated mesoporous silicon particles for advanced lithium-ion battery anodes. ACS Nano 12, 3853-3864 (2018).

29. Luo, W. et al. Surface and interface engineering of silicon-based anode materials for lithium-ion batteries. Adv. Energy Mater. 7, 1701083 (2017).

30. Fang, S. et al. Raspberry-like nanostructured silicon composite anode for high-performance lithium-ion batteries. ACS Appl. Mater. Inter $\mathbf{9}$, 18766-18773 (2017)

31. Ryu, I., Choi, J. W., Cui, Y. \& Nix, W. D. Size-dependent fracture of Si nanowire battery anodes. J. Mech. Phys. Solids 59, 1717-1730 (2011).
32. Lee, J. I. et al. High-performance silicon-based multicomponent battery anodes produced via synergistic coupling of multifunctional coating layers. Energy Environ. Sci. 8, 2075-2084 (2015).

33. Jia, H. P. et al. A novel approach to synthesize micrometer-sized porous silicon as a high performance anode for lithium-ion batteries. Nano Energy $\mathbf{5 0}$, 589-597 (2018).

34. Yoon, T. et al. Mesoporous silicon hollow nanocubes derived from metalorganic framework template for advanced Li-ion battery anode. ACS Nano 11, 4808-4815 (2017)

35. Gauthier, M. et al. A low-cost and high performance ball-milled Si-based negative electrode for high-energy Li-ion batteries. Energy Environ. Sci. 6, 2145-2155 (2013).

36. Song, J. X. et al. Micro-sized silicon-carbon composites composed of carboncoated sub-10 nm Si primary particles as high-performance anode materials for lithium-ion batteries. J. Mater. Chem. A 2, 1257-1262 (2013).

37. Sohn, H. S. et al. Semimicro-size agglomerate structured silicon-carbon composite as an anode material for high performance lithium-ion batteries. J. Power Sources 334, 128-136 (2016).

38. An, Y. et al. Green, scalable, and controllable fabrication of nanoporous silicon from commercial alloy precursors for high-energy lithium-ion batteries. ACS Nano 12, 4993-5002 (2018)

39. Jin, Y. et al. Understanding fluoroethylene carbonate and vinylene carbonate based electrolytes for $\mathrm{Si}$ anodes in lithium ion batteries with NMR spectroscopy. J. Am. Chem. Soc. 140, 9854-9867 (2018).

40. Jeong, S. et al. Etched graphite with internally grown $\mathrm{Si}$ nanowires from pores as an anode for high density Li-ion batteries. Nano. Lett. 13, 3403-3407 (2013).

41. Choi, J. W. et al. Metal current collector-free freestanding silicon-carbon 1D nanocomposites for ultralight anodes in lithium ion batteries. J. Power Sources 195, 8311-8316 (2010).

42. Wang, B. et al. High volumetric capacity silicon-based lithium battery anodes by nanoscale system engineering. Nano. Lett. 13, 5578-5584 (2013).

43. Kovalenko, I. et al. A major constituent of brown algae for use in highcapacity Li-ion batteries. Science 334, 75-79 (2011).

44. Yang, J. et al. Self-healing sei enables full-cell cycling of a silicon-majority anode with a coulombic efficiency exceeding 99.9\%. Energy Environ. Sci. 10, 580-592 (2017).

45. Lin, D. et al. High tap density secondary silicon particle anodes by scalable mechanical pressing for lithium-ion batteries. Energy Environ. Sci. 8, 2371-2376 (2015)

46. Hassoun, J., Lee, K. S., Sun, Y. K. \& Scrosati, B. An advanced lithium ion battery based on high performance electrode materials. J. Am. Chem. Soc. 133, 3139-3143 (2011).

47. Xiao, Q. F. et al. Inward lithium-ion breathing of hierarchically porous silicon anodes. Nat. Commun. 6, 8844 (2015).

48. Zhang, Q. et al. Harnessing the concurrent reaction dynamics in active $\mathrm{Si}$ and Ge to achieve high performance lithium-ion batteries. Energy Environ. Sci. 11, 669-681 (2018).

49. Wang, L. et al. Highly stretchable conductive glue for high-performance silicon anodes in advanced lithium-ion batteries. Adv. Funct. Mater. 28, 1704858 (2018)

50. Park, J. K. (ed.) Principles and applications of lithium secondary batteries (John Wiley \& Sons, Weinheim 2012).

51. Jung, C. H., Choi, J., Kim, W. S. \& Hong, S. H. A nanopore-embedded graphitic carbon shell on silicon anode for high performance lithium ion batteries. J. Mater. Chem. A 6, 8013-8020 (2018).

52. Uchida, H. et al. Synthesis of magnesium silicon nitride by the nitridation of powders in the magnesium-silicon system. J. Ceram. Soc. Jpn 105, 934-939 (1997).

53. Obrovac, M. N., Christensen, L., Le, D. B. \& Dahn, J. R. Alloy design for lithium-ion battery anodes. J. Electrochem. Soc. 154, A849-A855 (2007).

54. Li, X. K. et al. In-situ electron microscopy observation of electrochemical sodium plating and stripping dynamics on carbon nanofiber current collectors. Nano Energy 42, 122-128 (2017).

\section{Acknowledgements}

This work was financially supported by National Natural Science Foundation of China (No. 51572100, 21875080, 51504171, 21703185, and 61434001), Major Project of Technology Innovation of Hubei Province (2018AAA011), HUST Key Interdisciplinary Team Project (2016JCTD101), Wuhan Yellow Crane Talents Program, and City University of Hong Kong Applied Research Grant (ARG) No. 9667122 and Hong Kong Research Grants Council (RGC) General Research Funds (GRF) No. CityU 11205617. The authors are grateful for the facility support provided by the Nanodevices and Characterization Centre of WNLO-HUST and Analytical and Testing Center of HUST. The authors thank Prof. Yong Guan (National Synchrotron Radiation Laboratory, Hefei, China) and Prof. Yonghui Song (University of Science and Technology of China) for Synchrotron radiation 3D tomographic reconstruction images of the AMPSi and also thank Prof. Qihui Wu (Jimei University) for XPS characterizations. 


\section{Author contributions}

K.H. designed the idea and protocol of this work. W.A. and B.G. prepared the materials, carried out the thermogravimetric analysis, XRD, BET and mercury porosimetry and cowrote the draft. W.A., B.G., J.F. and B.X. conducted the electrochemical tests. S.M. obtained the SEM images. L.W. carried out the TEM characterizations. B.G. and Q.Z. obtained and analyzed the in situ TEM. K.H., W.A., B.G. and P.K.C. discussed the results and co-wrote the manuscript.

\section{Additional information}

Supplementary Information accompanies this paper at https://doi.org/10.1038/s41467019-09510-5.

Competing interests: The authors declare no competing interests.

Reprints and permission information is available online at http://npg.nature.com/ reprintsandpermissions/

Journal peer review information: Nature Communications thanks the anonymous reviewer (s) for their contribution to the peer review of this work. Peer reviewer reports are available.
Publisher's note: Springer Nature remains neutral with regard to jurisdictional claims in published maps and institutional affiliations.

(c) (i) Open Access This article is licensed under a Creative Commons Attribution 4.0 International License, which permits use, sharing, adaptation, distribution and reproduction in any medium or format, as long as you give appropriate credit to the original author(s) and the source, provide a link to the Creative Commons license, and indicate if changes were made. The images or other third party material in this article are included in the article's Creative Commons license, unless indicated otherwise in a credit line to the material. If material is not included in the article's Creative Commons license and your intended use is not permitted by statutory regulation or exceeds the permitted use, you will need to obtain permission directly from the copyright holder. To view a copy of this license, visit http://creativecommons.org/ licenses/by/4.0/.

(C) The Author(s) 2019 